Case Report

\title{
An unusual occurrence of giant primary osteosarcoma of chest wall in adult: case report and review of literature
}

\author{
Jeetendar Paryani*, Sameer Gupta, Parijat Suryavanshi, Shashi Singh Pawar
}

Department of Surgical Oncology, King George's Medical University Lucknow, Uttar Pradesh, India

Received: 17 December 2018

Accepted: 04 February 2019

\section{*Correspondence:}

Dr. Jeetendar Paryani,

E-mail: drjeetendar2004@gmail.com

Copyright: () the author(s), publisher and licensee Medip Academy. This is an open-access article distributed under the terms of the Creative Commons Attribution Non-Commercial License, which permits unrestricted non-commercial use, distribution, and reproduction in any medium, provided the original work is properly cited.

\begin{abstract}
Osteosarcoma is most frequently occurring bone malignancy which commonly occurs in the ends of the long bone. Usually osteosarcomas do not involve the bones of the chest wall. 22 year old patient presented with swelling in left anterior chest wall gradually enlarging over the period of 1 year accompanied by dull aching pain in the same. On examination there was $30 \times 25 \mathrm{~cm}$ large hard irregular swelling which was fixed to chest wall. CECT Thorax was suggestive of $30 \times 25 \times 18 \mathrm{~cm}$ sized soft tissue lesion involving 3, 4, 5 rib involvement with sunburst periosteal reaction. Mass is having large extrathoracic with small intrathoracic extensions. Moderate pleural effusion was noted. Core biopsy of mass identified the tumor as osteosarcoma. Primary malignant bone tumors of the chest wall are very rare entity. Of these tumors chondrosarcomas are the most frequent. Chondrosarcoma are chemo-resistant as compared to osteosarcomas. Management of such tumors should follow the same oncological principles of resection with wide margins whenever possible. Neoadjuvant chemotherapy may be given in cases of responsive etiologies like Ewing sarcoma or osteosarcoma. These malignancies generally have poor prognosis.
\end{abstract}

Keywords: Giant, Osteosarcoma, Chest wall, Rib

\section{INTRODUCTION}

Osteosarcoma is one of the most frequent bone sarcomas occurring primarily in metaphysis of long bones. ${ }^{1,2}$ The most age group affected in adolescence though it rarely might occur in adults. Osteosarcoma less frequently affects the flat bones of the body, of which pelvic bones are most commonly affected. Chest wall involvement is exceedingly rare by a primary osteosarcoma. ${ }^{1,2,3}$ These pose a unique diagnostic and management challenge to the clinician. We here describe a rare occurrence of a huge chest wall osteosarcoma in 22 year adult patient.

\section{CASE REPORT}

22 year old patient presented with swelling in left anterior chest wall gradually enlarging over the period of 1 year accompanied by dull aching pain in the same. On examination there was $30 \times 25 \mathrm{~cm}$ large hard irregular swelling which was fixed to chest wall (Figure 1).

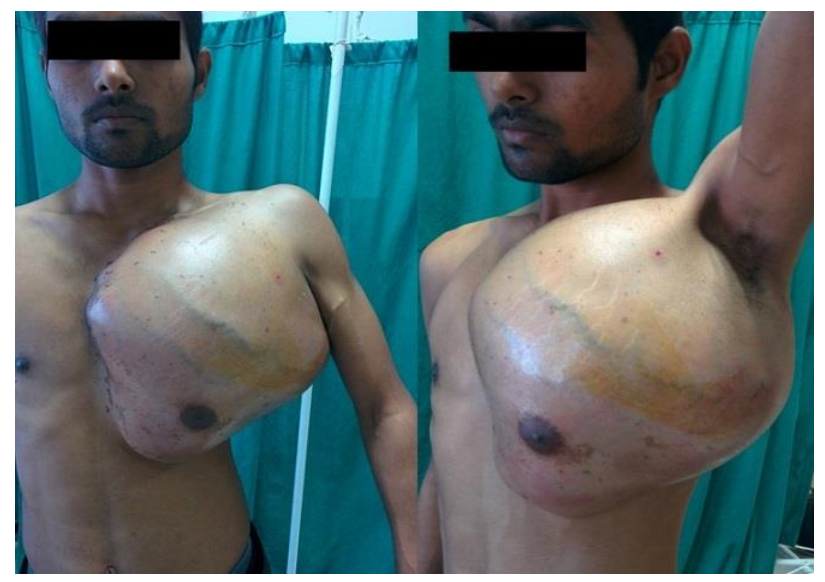

Figure 1: Clinical photographs of the patient. 
CECT thorax was suggestive of $30 \times 25 \times 18 \mathrm{~cm}$ sized soft tissue lesion involving $3,4,5$ rib involvement with sunburst periosteal reaction. Mass is having large extrathoracic with small intrathoracic extensions. Moderate pleural effusion was noted (Figure 2).

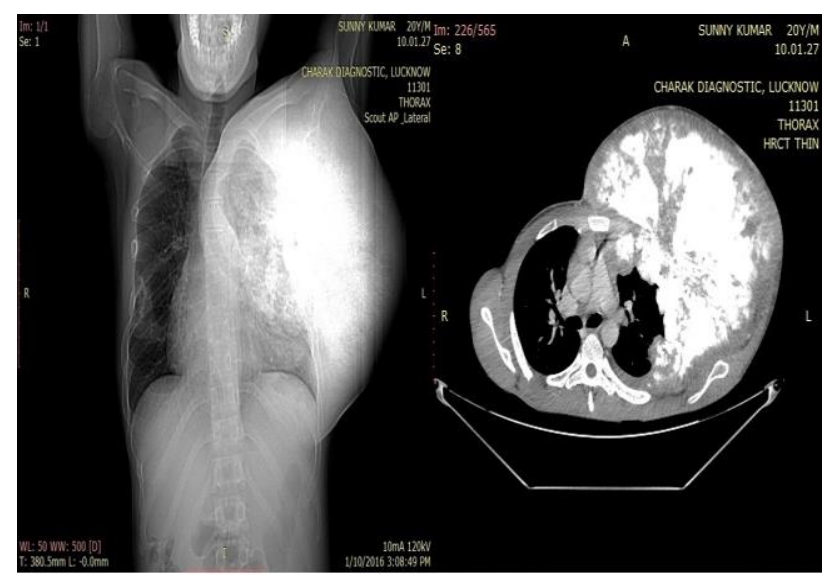

Figure 2: CECT Image of the patient.

Core biopsy of mass identified the tumor as osteosarcoma. Patient was started on cisplatin and doxorubicin based neoadjuvant chemotherapy. Unfortunately patient succumbed to the disease after $2^{\text {nd }}$ cycle.

\section{DISCUSSION}

Primary malignant bone tumours of the chest wall are very rare entity. ${ }^{1,2}$ Of these tumours chondrosarcomas are the most frequent. ${ }^{2}$ These are mainly low-grade. Cases originating from the ribs are infrequent and have been reported mainly in the pediatric population. ${ }^{3}$

Osteosarcoma occurring in flat bones is an uncommon entity. In a large study comprising of 49 cases of primary malignant chest wall tumors there were no osteosarcomas reported. ${ }^{4}$ Involvement of flat bones may be seen as a metastatic process or secondary to chemotherapy, but a primary osteosarcoma of the chest wall is rare. ${ }^{5}$ In another study primary rib osteosarcoma was only observed in one $(0.5 \%)$ of 190 patients with osteosarcoma in 25 years in pediatric population. ${ }^{6}$ The fact that primary osteosarcoma occurs so rarely at this site and varying radiological images, these tumors are often confused with other bone lesions or other malignancies like chondrosarcoma, fibrosarcoma or even metastatic tumor. Our patient presented a rare scenario of an adult having a primary osteosarcoma of the chest wall involving multiple ribs.

These tumors will frequently present as enlarging, painful masses at the anterior chest wall or less commonly from the paravertebral region. Patients sometimes may present with painless mass, which might be due to the fact that the ribs and the sternum are non-weight-bearing bones. ${ }^{2}$
Osteosarcomas generally require multimodal treatment in form of chemotherapy and surgery. Management guidelines for a rib primary osteosarcoma are not clear due to rarity of the case and scant available literature. Wide en bloc resection with negative margins is necessary in all cases of malignant chest wall tumours including osteosarcoma but neoadjuvant chemotherapy may be considered in cases where in the pre-operative diagnosis of osteosarcoma is established..$^{7,8}$ The overall prognosis of osteosarcoma in flat bones remains despite aggressive surgery and multi-agent chemotherapy; previous study reported a 5-year survival of only about $27 \%{ }^{9}$

The patient is our study presented with anterior chest mass which on biopsy was osteosarcoma. He was started on neoadjuvant chemotherapy but succumbed to the disease.

This report was attempted to illustrate a rare scenario which poses a major diagnostic and therapeutic challenge to the treating clinicians. Gradually with more literature we might be able to formulate better guidelines and deal with primary osteosarcomas of chest wall.

Funding: No funding sources

Conflict of interest: None declared

Ethical approval: Not required

\section{REFERENCES}

1. Krishnamurthy A, Arulmolichelvan A. The Management Challenges in an Unusual Case of Primary Osteosarcoma of the Rib in an Adult Patient. Ind J Surg. 2017;79(4):363-6.

2. Friesenbichler J, Leithner A, Maurer-Ertl W, Szkandera J, Sadoghi P, Frings A, et al. Surgical therapy of primary malignant bone tumours and soft tissue sarcomas of the chest wall: a two-institutional experience. Int Orthop. 2014;38(6):1235-40.

3. Low-grade central osteosarcoma of the rib.Yamaguchi T, Shimizu K, Koguchi Y, Saotome K, Ueda Y. Skeletal Radiol. 2005;34(8):490-3.

4. Surgical treatment of primary malignant chest wall tumours.Sabanathan S, Shah R, Mearns J. Eur J Cardiothorac Surg. 1997;11(6):1011-6.

5. Kellie SJ, Pratt CB, Parham DM, Fleming ID, Meyer WH, Rao BN. Sarcomas (other than Ewing's) of flat bones in children and adolescents. Cancer. 1990;65:1011.

6. Bay SB, Kebudi R, İribaş A, Ömer Görgün, Fulya Ağaoğlu, Feryal Gün, et al. Osteosarcoma of the rib: A rare presentation. Turk Pediatri Ars. 2018;53(1):57-60.

7. Xie P, Huang J. Primary Osteosarcoma of the Rib Identified on Bone Scintigraphy. Clin Nucl Med. 2016;41(5):390-1.

8. $\mathrm{Xu} \mathrm{G}$, Zheng K. Successful management of early recurrence after surgery for primary rib 
osteosarcoma in an adult. Interact Cardiovasc Thorac Surg. 2013;17(2):431-2.

9. Misiak P, Jabłoński S. High-grade surface osteosarcoma of the rib-a case report. Pol Merkur Lekarski. 2015;39:40-2.
Cite this article as: Paryani J, Gupta S, Suryavanshi $\mathrm{P}$, Pawar SS. An unusual occurrence of giant primary osteosarcoma of chest wall in adult: case report and review of literature. Int J Res Orthop 2019;5:356-8. 